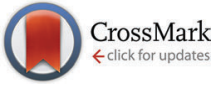

Cite this: Chem. Commun., 2015, 51,2270

Received 5th December 2014 Accepted 22nd December 2014

DOI: $10.1039 / c 4 c c 09730 k$

www.rsc.org/chemcomm

\section{Organocatalytic one-pot 1,4-/1,6-/1,2-addition sequence for the stereocontrolled formation of six consecutive stereocenters $\dagger$}

\author{
Pankaj Chauhan, Suruchi Mahajan, Gerhard Raabe and Dieter Enders*
}

An unprecedented stereoselective organocatalytic one-pot 1,4-/ $1,6-/ 1,2$-addition sequence between $\beta$-dicarbonyl compounds, $\beta$-nitroalkenes and 4-nitro-5-styrylisoxazoles sequentially catalyzed by low loading of a squaramide catalyst and an achiral base has been developed. The protocol opens an efficient entry to isoxazole bearing cyclohexanes with six consecutive stereogenic centers including one tetrasubstituted carbon in good yields and excellent diastereo- and enantioselectivities.

Over the last ten years, asymmetric organocatalytic cascade reactions have emerged as a powerful strategy for the synthesis of complex molecules bearing multiple stereogenic centers in a highly stereocontrolled fashion. ${ }^{1}$ These one-pot organocatalytic reactions were successfully employed for the creation of cyclohexane ring systems bearing up to six stereocenters. ${ }^{2}$ Most of these triple cascade reactions are governed by more common 1,4-/1,4-/1,2 addition sequences. Another important class of addition reactions involving the enantioselective 1,6-addition to control the formation of a remote stereocenter is more challenging and less explored in comparison to the other addition variants. ${ }^{3}$ Moreover, organocatalytic cascade reactions using all possible types of addition reactions, i.e. 1,4-/1,6-/1,2-addition reactions, are not known so far. Hence we took the challenge to develop a new stereoselective one-pot organocascade sequence using 1,4-/1,6-/1,2-additions (Scheme 1).

In addition, the isoxazole core is present in various important naturally occurring and synthetic bioactive molecules (Fig. 1). For example, compounds A-D are $\beta$-lactamase-resistant antibiotics, ${ }^{4}$ while an isoxazole containing natural product $\mathbf{E}$ is a powerful neurotoxin, which is used as a brain-lesioning agent. ${ }^{5}$ A synthetic androgenic steroid danazol $\mathbf{D}$ bearing an isoxazole ring suppresses the production of gonadotrophins and also has some weak androgenic effects. ${ }^{6}$ Moreover, isoxazoles serve as

Institute of Organic Chemistry, RWTH Aachen University, Landoltweg 1, 52074 Aachen, Germany. E-mail: enders@rwth-aachen.de; Fax: +49 2418092127 $\dagger$ Electronic supplementary information (ESI) available. CCDC 1037530. For ESI and crystallographic data in CIF or other electronic format see DOI: 10.1039/c4cc09730k
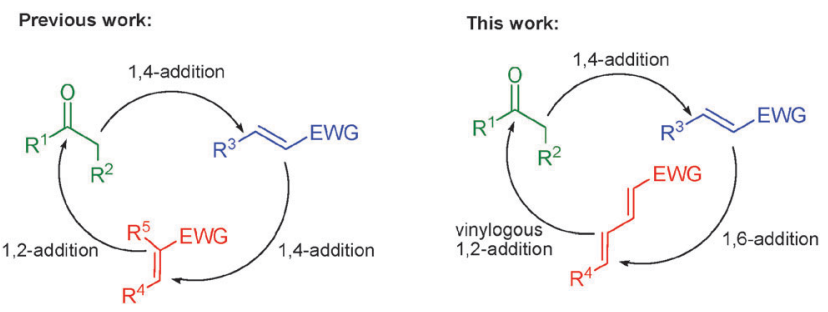

Scheme 1 Enantioselective strategies for the construction of cyclohexane rings bearing multiple stereogenic centers.
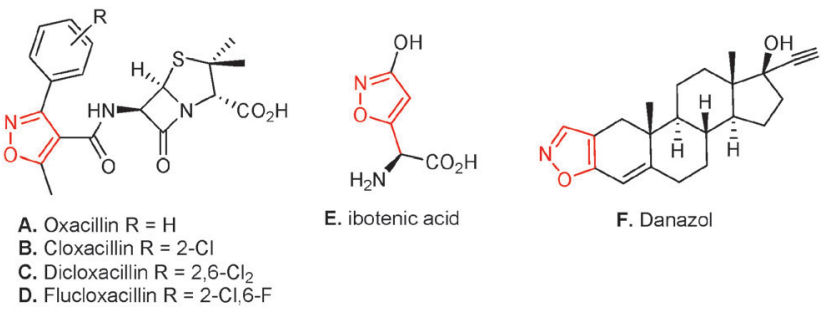

C. Dicloxacillin $\mathrm{R}=2,6-\mathrm{Cl}_{2}$

Fig. 1 Enantiopure drugs and bioactive natural products bearing an isoxazole ring.

precursors for the synthesis of various synthetically useful organic compounds. ${ }^{7}$ Thus, the development of efficient asymmetric methods for the synthesis of isoxazole ring containing molecules can provide a new series of potentially bioactive molecules.

Recently, organo- and metal-catalyzed 1,6-additions to 4-nitro5 -styrylisoxazoles emerged as an efficient method to generate enantiopure isoxazole derivatives bearing one or two stereocenters. ${ }^{8,9}$ However, the 4-nitro-5-styrylisoxazoles remained less explored substrates in stereoselective cascade reactions. ${ }^{9 d, g}$ Very recently, Jørgensen's group utilized 4-nitro-5-styrylisoxazoles in trienamine-mediated asymmetric [4+2] cycloaddition reactions to afford cyclohexene products bearing three vicinal stereocenters. ${ }^{10}$ Herein we report a novel cascade reaction involving a 1,4-/1,6-/vinylogous 1,2-addition sequence to access enantiopure cyclohexane rings bearing as many as six contiguous 
Table 1 Optimizations of the reaction conditions ${ }^{a}$

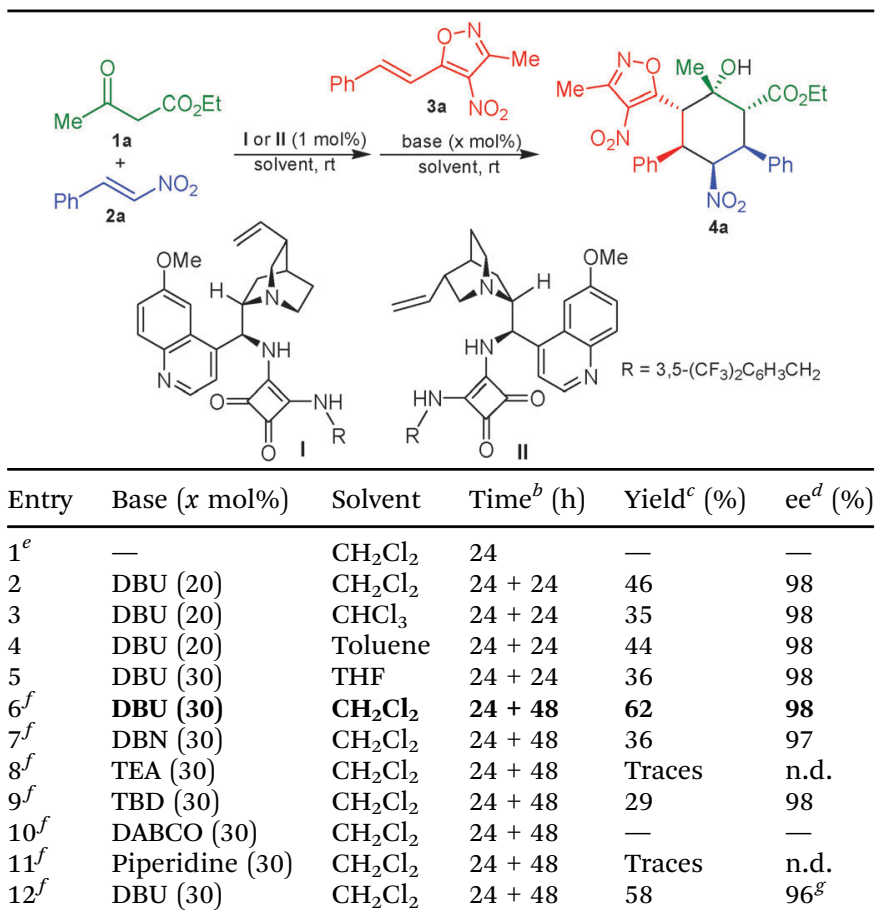

${ }^{a}$ Reaction conditions: $0.2 \mathrm{mmol}$ of $1 \mathrm{a}, 0.2 \mathrm{mmol}$ of $2 \mathrm{a}, 1 \mathrm{~mol} \%$ of $\mathbf{I}$ $0.24 \mathrm{mmol}$ of $3 \mathrm{a}$ and $x \mathrm{~mol} \%$ of base $\left(0.1 \mathrm{M}\right.$ in solvent). ${ }^{b}$ Time in hours for both reaction steps. ${ }^{c}$ Yield of isolated 4 a after column chromatography. ${ }^{d}$ Enantiomeric excess of the major diastereomer (>20:1 dr) determined by HPLC analysis on a chiral stationary phase. ${ }^{e}$ All the reactants were added in one step. ${ }^{f} 2$ equivalents of $3 \mathbf{a}$ were used. ${ }^{g}$ ee value of ent-4a synthesized by using catalyst II.

stereogenic centers, sequentially catalyzed by low loading of a cinchona derived squaramide ${ }^{11}$ and an achiral base.

Initially, we started our investigation with a squaramide $\mathbf{I}$ (1 mol\%) catalyzed one-pot three component reaction between ethyl acetoacetate (1a), $\beta$-nitrostyrene (2a) and 4-nitro-5-styrylisoxazole (3a) (Table 1, entry 1). However our attempt to obtain the desired cyclohexane ring failed completely, and only the formation of the Michael adduct was observed. ${ }^{12}$ We envisaged that the squaramide catalyst was not enough active to generate a nitronate anion in the corresponding Michael adduct to initiate a domino 1,6-/vinylogous 1,2-addition sequence. Thus, a sequential reaction was performed involving a squaramide $\mathbf{I}$ catalyzed Michael addition of the $\beta$-ketoester $\mathbf{1 a}$ to the $\beta$-nitrostyrene $\mathbf{2 a}$, followed by the addition of $3 \mathrm{a}$ and a catalytic amount of DBU (20 mol\%) (entry 2). To our delight, the desired cyclohexane 4a was obtained in $46 \%$ yield with excellent stereoselectivity (98\% ee and $>20: 1 \mathrm{dr}$ ). Further optimization of the reaction conditions by screening different solvents (entries 3-5) and bases (entries 6-11) showed that $30 \mathrm{~mol} \%$ of $\mathrm{DBU}$ in $\mathrm{CH}_{2} \mathrm{Cl}_{2}$ provides a maximum yield of $62 \%$ and excellent stereoselectivity (entry 6). The use of a quinidine derived squaramide catalyst II led to the opposite enantiomer of the cyclohexane ent-4a with a similar yield, ee and dr (entry 12).

Once equipped with optimized reaction conditions, we evaluated the substrate scope at a $0.5 \mathrm{mmol}$ scale of the $\beta$-dicarbonyl compounds and the $\beta$-nitrostyrenes (Table 2). The various nitroalkenes
Table 2 Substrate scope ${ }^{a}$

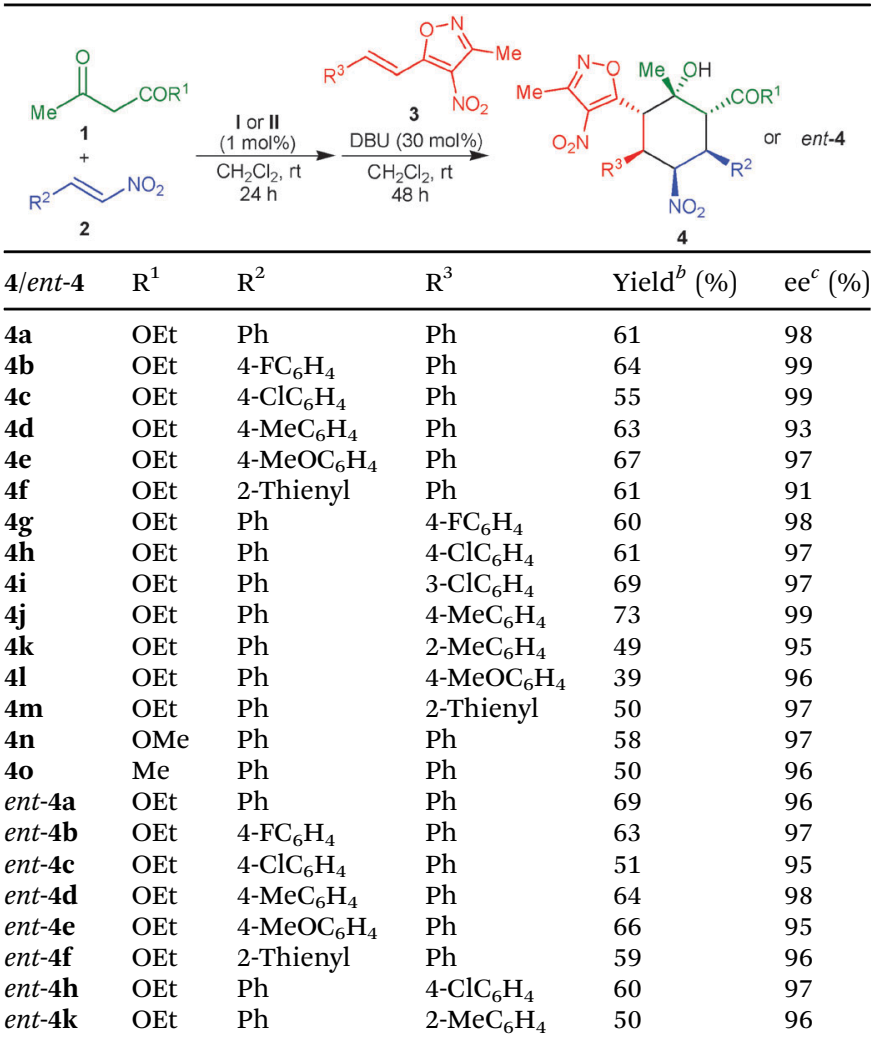

${ }^{a}$ Reaction conditions: $0.5 \mathrm{mmol}$ of $1,0.5 \mathrm{mmol}$ of $2,1 \mathrm{~mol} \%$ of I (entry 1-17) or II, $1.0 \mathrm{mmol}$ of 3 and $30 \mathrm{~mol} \%$ of DBU $\left(0.1 \mathrm{M}\right.$ in $\left.\mathrm{CH}_{2} \mathrm{Cl}_{2}\right) .{ }^{b}$ Yield of isolated product after column chromatography. ${ }^{c}$ Enantiomeric excess of the major diastereomer determined by HPLC analysis on a chiral stationary phase.

bearing electron withdrawing and electron donating groups gave rise to the corresponding isoxazole products $\mathbf{4 b - e}$ in $55-67 \%$ yield and excellent stereoselectivities ( $>20: 1 \mathrm{dr}$ and $93-99 \%$ ee). The nitroalkenes bearing a heteroaromatic group also worked well in this cascade sequence to provide the desired product $4 \mathrm{f}$ in $61 \%$ yield and $91 \%$ ee. Further screening of different 4-nitro-5-styrylisoxazoles bearing electron withdrawing and electron releasing substituents on the aryl ring as well as heteroaryl group provided a direct access to the corresponding cyclohexanes $\mathbf{4 g}-\mathbf{m}$ in good yields and high enantioselectivities (95-99\% ee). The methyl acetoacetate and acetyl acetone were also tolerated under this one-pot protocol to give rise to the respective products $\mathbf{4 n}$ and $\mathbf{4 o}$ in good yields and excellent stereoselectivities. Employing a pseudo-enantiomeric aminosquaramide catalyst II successfully led to the formation of the enantiomers of $\mathbf{4 a - f}, \mathbf{4 h}$ and $\mathbf{4 l}$ in very good yields (51-69\%) and again excellent asymmetric inductions ( $>20: 1 \mathrm{dr}$ and $95-98 \%$ ee).

The absolute configuration of the products $4 \mathbf{4}-\mathbf{o}$ can be assigned as (1S), $(2 S),(3 R),(4 S),(5 S)$ and $(6 R)$ on the basis of the X-ray crystallographic analysis of 4 a (Fig. 2) ${ }^{13}$

To demonstrate the practical and preparative application of this new organocascade 1,4-/1,6-/1,2-addition sequence, we performed a gram-scale reaction between 1a, 2a and 3a using a lower loading ( $0.5 \mathrm{~mol} \%$ ) of the squaramide I (Scheme 2). The desired product 4a was obtained in $57 \%$ yield with unchanged ee and dr values. 


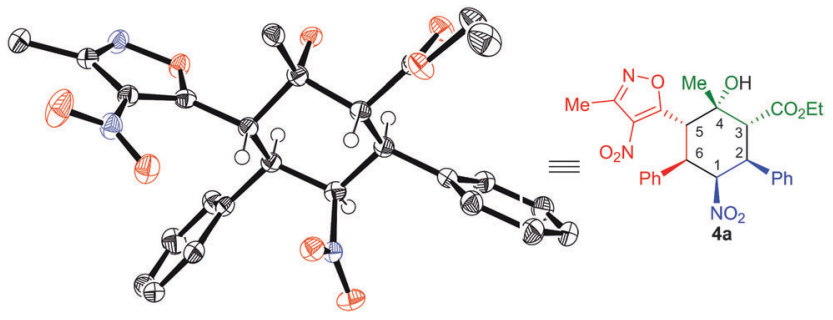

Fig. 2 X-ray structure of $\mathbf{4 a}$.

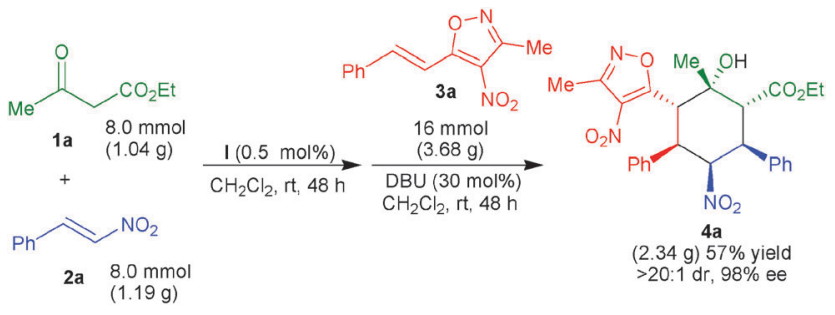

Scheme 2 Gram-scale 1,4-/1,6-/1,2-addition sequence.

The enantiomeric purity could be enriched to $>99 \%$ ee after a single crystallization of the product.

In conclusion, we have developed a novel 1,4-/1,6-/1,2-addition cascade sequence catalyzed sequentially by low loading of a cinchona-derived squaramide and a commercially available achiral base to afford a series of highly substituted cyclohexane derivatives bearing six consecutive stereogenic centers in good yields and excellent stereoselectivities. The enantiomeric cyclohexanes are also easily synthesized on a same level of asymmetric induction by employing a pseudo-enantiomeric squaramide catalyst. A successful gram-scale reaction documents the preparative utility of this organocascade protocol.

Support from the European Research Council (ERC Advanced Grant 320493 "DOMINOCAT") is gratefully acknowledged. We thank BASF SE for the donation of chemicals.

\section{Notes and references}

1 For selected reviews on organocatalytic domino/cascade reactions, see: (a) D. Enders, C. Grondal and M. R. M. Hüttl, Angew. Chem., Int. Ed., 2007, 46, 1570; (b) X. Yu and W. Wang, Org. Biomol. Chem., 2008, 6, 2037; (c) C. Grondal, M. Jeanty and D. Enders, Nat. Chem., 2010, 2, 167; (d) Ł. Albrecht, H. Jiang and K. A. Jørgensen, Angew. Chem., Int. Ed., 2011, 50, 8492; (e) A. Moyano and R. Rios, Chem. Rev., 2011, 111, 4703; $(f)$ A. Grossmann and D. Enders, Angew. Chem., Int. Ed., 2012, 51, 314; $(g)$ H. Pellissier, Adv. Synth. Catal., 2012, 354, 237; (h) C. M. R. Volla, I. Atodiresei and M. Rueping, Chem. Rev., 2014, 114, 2390; For a recent highlight, see: (i) P. Chauhan and D. Enders, Angew. Chem., Int. Ed., 2014, 53, 1485.

2 For a recent review, see: (a) S. Goudedranche, W. Raimondi, X. Bugaut, T. Constantieux, D. Bonne and J. Rodriguez, Synthesis, 2013, 1909; for selected examples, see: (b) D. Enders, M. R. M. Hüttl, C. Grondal and G. Raabe, Nature, 2006, 441, 861; (c) D. Enders, M. R. M. Hüttl, Y. Runsink, G. Raabe and B. Wendt, Angew. Chem., Int. Ed., 2007, 46, 467; (d) D. Enders, M. R. M. Hüttl, G. Raabe and J. W. Bats, Adv. Synth. Catal., 2008, 350, 267; (e) P. G. McGarraugh and S. E. Brenner, Org. Lett., 2009, 11, 5654; $(f)$ Y. Wang, R.-G. Han, Y.-L. Zhao, S. Yang, P.-F. Xu and D. J. Dixon, Angew. Chem., Int. Ed., 2009, 48, 9834; $(g)$ K. Jiang, Z.-J. Jia, S. Chen, L. Wu and Y.-C. Chen, Chem. - Eur. J., 2010, 16, 2852; (h) O. Baslé, W. Raimondi, M. M. Sanchez Duque, D. Bonne, T. Constantieux and J. Rodriguez, Org. Lett., 2010, 12, 5246; (i) D. Enders, B. Schmid and
N. Erdmann, Synthesis, 2010, 2271; ( $j$ ) M. Rueping, K. L. Haack, W. Ieawsuwan, H. Sundén, M. Blanco and F. R. Schoepke, Chem. Commun., 2011, 47, 3828; ( $k$ ) C. Cassani, X. Tian, E. C. Escudero-Adán and P. Melchiorre, Chem. Commun., 2011, 47, 233; (l) A. Zea, A.-N. R. Alba, A. Mazzanti, A. Moyano and R. Rios, Org. Biomol. Chem., 2011, 9, 6519; ( $m$ ) D. Enders, A. Greb, K. Deckers, P. Selig and C. Merkens, Chem. - Eur. J., 2012, 18, 10226; (n) D. Enders, G. Urbanietz, E. Cassens-Sasse, S. Keeß and G. Raabe, Adv. Synth. Catal., 2012, 354, 1481; (o) W. Raimondi, M. M. Sanchez Duque, S. Goudedranche, A. Quintard, T. Constantieux, X. Bugaut, D. Bonne and J. Rodriguez, Synthesis, 2013, 1659; (p) X. Zeng, Q. Ni, G. Raabe and D. Enders, Angew. Chem., Int. Ed., 2013, 52, 2977; (q) P. Chauhan, G. Urbanietz, G. Raabe and D. Enders, Chem. Commun., 2014, 50, 6853; (r) P. Chauhan, S. Mahajan, C. C. J. Loh, G. Raabe and D. Enders, Org. Lett., 2014, 16, 2954; (s) P. Sun, C.-Y. Meng, F. Zhoua, X.-S. Li and J.-W. Xie, Tetrahedron, 2014, 70, 9330; $(t)$ J. I. Martínez, L. Villar, U. Uria, L. Carrillo, E. Reyes and J. L. Vicario, Adv. Synth. Catal., 2014, 355, 3627.

3 For selected reviews and highlights on 1,6-addition reactions, see: (a) A. G. Csaký, G. de la Herrán and M. C. Murcia, Chem. Soc. Rev., 2010, 39, 4080; (b) A. T. Biju, ChemCatChem, 2011, 3, 1847; (c) E. M. P. Silva and A. M. S. Silva, Synthesis, 2012, 3109; (d) M. J. Lear and Y. Hayashi, ChemCatChem, 2013, 5, 3499; (e) I. D. Jurberg, I. Chatterjee, R. Tannert and P. Melchiorre, Chem. Commun., 2013, 49, 4869; for recent examples, see: $(f)$ X. Tian, Y. Liu and P. Melchiorre, Angew. Chem., Int. Ed., 2012, 51, 6439; $(g)$ L. Dell'Amico, Ł. Albrecht, T. Naicker, P. H. Poulsen and K. A. Jørgensen, J. Am. Chem. Soc., 2013, 135, 8063; (h) W.-D. Chu, L.-F. Zhang, X. Bao, X.-Y. Zhao, C. Zeng, J.-Y. Du, G.-B. Zhang, F.-X. Wang, X.-Y. Ma and C.-A. Fan, Angew. Chem., Int. Ed., 2013, 52, 9229; (i) L. Caruana, F. Kniep, T. K. Johansen, P. H. Poulsen and K. A. Jørgensen, J. Am. Chem. Soc., 2014, 136, 15929; $(j)$ K. Akagawa, N. Nishi, J. Sen and K. Kudo, Org. Biomol. Chem., 2014, 12, 3581.

4 (a) R. Sutherland, E. A. P. Croydon and G. N. Rolinson, Br. Med. J., 1970, 4, 455; (b) G. Miranda-Novales, B. E Leaños-Miranda, M. Vilchis-Pérez and F. Solórzano-Santos, Ann. Clin. Microbiol. Antimicrob., 2006, 5, 25.

5 (a) O. Isacson, P. Brundin, P. A. T. Kelly, F. H. Gage and A. Björklund, Nature, 1984, 311, 458; (b) A. Becker, G. Grecksch, H.-G. Bernstein, V. Höllt and B. Bogerts, Psychopharmacology, 1999, 144, 333.

6 H. C. Neumann, G. O. Potts, W. T. Ryan and F. W. Stonner, J. Med. Chem., 1970, 13, 948.

7 P. G. Baraldi, A. Barco, S. Benetti, G. P. Pollini and D. Simoni, Synthesis, 1987, 857.

8 For selected examples of 4-nitro-5-styrylisoxazoles in non-enantioselective 1,6-addition reactions, see: (a) S. Chimichi, F. D. Sio, D. Donatic, P. S. Fantoni and M. F. A. Adamo, Tetrahedron Lett., 2002, 43, 4157; (b) S. Bruschi, S. Suresh, L. Piras and M. F. A. Adamo, Tetrahedron Lett., 2008, 49, 7406; (c) M. Nagabelli and M. F. A. Adamo, Tetrahedron Lett., 2007, 48, 4703; (d) V. R. Konda and M. F. A. Adamo, Org. Lett., 2007, 9, 303; (e) F. Fini, M. Naabelli and M. F. A. Adamo, Adv. Synth. Catal., 2010, 352, 3163; $(f)$ D. S. Illera, S. Suresh, M. Moccia, G. Bellini, M. Saviano and M. F. A. Adamo, Tetrahedron Lett., 2012, 53, 1808; $(g)$ M. N. Reddy, K. G. Reddy, S. R. Krishna and E. Rajanarendar, Tetrahedron Lett., 2012, 53, 2909.

9 For selected examples of 4-nitro-5-styrylisoxazoles in enantioselective 1,6-addition reactions, see: (a) M. Nagabelli and M. F. A. Adamo, Org. Lett., 2008, 10, 1807; (b) A. Baschieri, L. Bernardi, A. Ricci, S. Suresh and M. F. A. Adamo, Angew. Chem., Int. Ed., 2009, 48, 9342; (c) Q.-L. Pei, H.-W. Sun, Z.-J. Wu, X.-L. Du, X.-M. Zhang and W.-C. Yuan,J. Org. Chem., 2011, 76, 7849; (d) H.-W. Sun, Y.-H. Liao, Z.-J. Wu, H.-Y. Wang, X.-M. Zhang and W.-C. Yuan, Tetrahedron, 2011, 67, 3991; (e) C. D. Fiandra, L. Piras, F. Fini, P. Disetti, M. Moccia and M. F. A. Adamo, Chem. Commun., 2012, 48, 3863; $(f)$ J.-L. Zhang, X.-H. Liu, X.-J. Ma and R. Wang, Chem. Commun., 2013, 49, 9329; $(g)$ R. J. Chew, Y. Huang, Y. Li, S. A. Pullarkat and P.-H. Leung, Adv. Synth. Catal., 2013, 355, 1403; (h) X.-L. Liu, W.-Y. Han, X.-M. Zhang and W.-C. Yuan, Org. Lett., 2013, $15,1246$.

10 Y. Li, F. J. López-Delgado, D. K. B. Jørgensen, R. P. Nielsen, H. Jiang and K. A. Jørgensen, Chem. Commun., 2014, 50, 15689.

11 For reviews on squaramides, see: (a) J. Alemán, A. Parra, H. Jiang and K. A. Jørgensen, Chem. - Eur. J., 2011, 17, 6890; (b) R. I. Storer, C. Aciro and L. H. Jones, Chem. Soc. Rev., 2011, 40, 2330.

12 (a) J. P. Malerich, K. Hagihara and V. H. Rawal, J. Am. Chem. Soc., 2008, 130, 14416; (b) H. Y. Bae, S. Some, J. S. Oh, Y. S. Lee and C. E. Song, Chem. Commun., 2011, 47, 9621; (c) Y.-F. Wang, R.-X. Chen, K. Wang, B.-B. Zhang, Z.-B. Lib and D.-Q. Xu, Green Chem., 2012, 14, 893.

13 CCDC 1037530 (for 4a). 